\title{
Scale-up of flat bladed mixer in orange juice concentrate process
}

\author{
S. R. Mostafa ${ }^{1}$, M. A. Sorour ${ }^{2}$, S. M. Bo Samri ${ }^{3}$ \\ ${ }^{1}$ Chemical Engineering Dept., Faculty of Eng., Cairo Univ., Giza. Egypt \\ ${ }^{2}$ Food Eng. and Packaging Dept., Food Tech. Research Institute, Agric. Research center, Giza, Egypt \\ ${ }^{3}$ Public Authority of Education Applied \& Training Healthy Science, Food Processing Nutrition, Kuwait, Kuwait \\ Email address: \\ Salwa_raafat@hotmail.com (S. R. Mostafa)manal.sorour@yahoo.com (M. A. Sorour), fsnd_1@yahoo.com (S. M. B. Samri)
}

\section{To cite this article:}

S. R. Mostafa, M. A. Sorour, S. M. Bo Samri. Scale-Up of Flat Bladed Mixer in Orange Juice Concentrate Process. Journal of Electrical and Electronic Engineering. Special Issue: Energy Conservation in Food Industry. Vol. 3, No. 2-1, 2015, pp. 1-5.

doi: 10.11648/j.ajee.s.2015030201.11

\begin{abstract}
Mixing of orange concentrates to be homogenized was investigated using flat - bladed impeller. The rheological properties of orange juice concentrate were studied over the range $10-70^{\circ} \mathrm{C}$, solid concentration $66 \mathrm{wt} \%$ and speed of spindle 50-250 rpm. Shear stress-shear rate data indicate that the concentrate behaves as non-Newtonian pesudoplastic fluid. Geometry was studied by varying the impeller to a column diameter. An impeller mixer was connected to an ammeter in order to predict the power of the mixer. The relation between a power number, blend number, pumping number and Reynolds's number were calculated at different $\mathrm{D} / \mathrm{T}$. Scale-up of the mixing process from the laboratory to the production plant scale was carried out utilizing the aforementioned correlations.
\end{abstract}

Keywords: Scale-Up, Mixing, Flow Behavior of Orange Juice, Power Number, Flat Bladed Mixer, Mixing of Shear Thinning Fluids

\section{Introduction}

Mixing processes are complex, multi-faceted in nature and require an understanding of the fluid flow behavior along with an understanding of the mechanical and power requirement aspects of the equipment. [1]

Mixing plays an important role in the chemical, biochemical and food industries. To obtain high-quality products and high-efficiency processes, mixing must satisfy not only the needs of heat and mass transfer, but also the required homogeneity in the vessel in the shortest possible time. It has been widely reported throughout the literature that mixing conditions are related to product quality in a variety of processes. [2-4]

Most of the chemical and allied process industries frequently use a mixing operation to increase the degree of homogeneity of a property such as viscosity, color, concentration, and temperature [5]. These industries often involve non-Newtonian fluids with a yield stress; namely, pulp suspension, food substances such as ketchup and mayonnaise, paint, cement, pigment slurries, certain polymer and biopolymer solutions and wastewater sludge. [6].
The mixing of carrot concentrate $(66 \%)$ to be homogenized were studied using a flat- bladed impeller. The relation between Power number, Blend number, Pumping number and Reynold's number were plotted at different $\mathrm{D} / \mathrm{T}$ ratio. Scale-up of the mixing process from the laboratory to the production plant scale was carried out utilizing the aforementioned correlations. [7]

The rheological properties of apricot jam puree over the range $30-80^{\circ} \mathrm{C}$, solid concentration $45,55,65 \mathrm{wt} \%$ of apricot jam puree, and speed of spindle 50-250 rpm were studied. Shear stress-Shear rate data indicated that the puree behaves as non-Newtonian pseudoplastic fluid which fitted well to power law. An impeller mixer was connected with Ammeter in order to predict the power of the mixer, then to predict the power number and Reynolds number at different temperatures and revolution per second. [8]

Experimental measurements on the influence of geometry of the pendulum agitators with clapping blades and of the physical parameters of mixed fluid on the homogenization time, the power consumption and the energy of mixing were analyzed and original formulas were proposed for the determination of the above mentioned mixing variables by 
Masiuk and Kawecka [9].

Scaling- up for product quality requires simultaneous consideration of both mixing and heat transfer and accordingly industrial laminar flow mixers and heat exchangers need to be specially designed [10-13].

The objectives of this paper are to develop the effect of impeller to tank diameter ratio $\mathrm{D} / \mathrm{T}$ on the plot of the dimensionless groups; power number, blend number, flow number, versus Reynold's number, then to use the obtained relationships to scale up the mixer process in non-Newtonian fluids. Since fluid rheology strongly impacts the design of an agitation system, a flow behavior investigation of the fluid (orange juice concentrate) is carried out to serve for the objectives of the paper.

\section{Material and Methods}

\subsection{Material}

Orange juice and its concentrate were prepared in ElMarwa company (6 October City) at $12 \%$ and $66 \%$ respectively.

\subsection{Method}

\subsubsection{Flow Behavior of Orange Juice Concentrates}

Rheological parameters (shear stress, shear rate, viscosity) of orange juice were measured at different temperatures using Brookfield Engineering labs DV-III Rheometer. The rheological properties of orange juice concentrate were studied over the range $4-70^{\circ} \mathrm{C}$, solid concentration $66 \mathrm{wt} \%$ of orange concentrates, and shear rate $2.2-22 \mathrm{sec}^{-1}$.

\subsubsection{Mixing of Orange Juice Concentrates}

The mixing of orange juice concentrates to be homogenized using flat-bladed impeller. The relation between Power number, Blend number, Pumping number and Reynold's number were calculated at different D/T. Scale-up of the mixing process from the laboratory to the production plant scale was carried out utilizing the aforementioned correlations.

There are several important dimensionless numbers that are required to design mixers. All must be determined experimentally for a given impeller configuration. These numbers can be used to quantify the performance characteristics of an impeller. Dimensionless numbers are affected by geometric factors, such as the ratio of impeller diameter (D) to tank diameter (T), D/T and the ratio of clearance from the tank bottom to tank diameter,C/T. [14-15]

The impeller power number, $\mathrm{N}_{\mathrm{P}}$, is used to predict the power of the mixer, $\mathrm{P}$, directly and torque, $\mathrm{t}$, indirectly:

$$
N_{P}=P / \rho N^{3} D^{5}
$$

Where, $\mathrm{N}_{\mathrm{p}}$ is the power number; $\mathrm{P}$ is the power of the mixer, watt; $\mathrm{D}$ is the diameter of the impeller, $\mathrm{m}$; $\mathrm{N}$ is revolutions per second and $\mathrm{p}$ is the density of the concentrate, $\mathrm{kg} / \mathrm{m}^{3}$.
The impeller blend number; $\mathrm{NB}$ is used to predict the blend time, $\theta$, in a a mixed process. number, $\mathrm{N}_{\mathrm{B}}$, attempts to predict the effect of impeller $\mathrm{D} / \mathrm{T}$ on the results:

$$
N_{B}=N \theta\left(\frac{D}{T}\right)^{2.3}
$$

Where, $\mathrm{N}_{\mathrm{B}}$ is the blend number; $\mathrm{N}$ is revolutions per second; $\mathrm{D}$ is the diameter of the impeller, $\mathrm{m}$; $\mathrm{T}$ is the tank diameter; $m$ and $\theta$ is the time in second.

The impeller pumping number, $\mathrm{N}_{\mathrm{Q}}$, is used to predict the impeller pumping rate, $\mathrm{q}$, directly and bulk fluid velocity, $\mathrm{V}_{\mathrm{bf}}$, indirectly.

$$
\begin{aligned}
& N_{Q}=q / N D^{2.3} \\
& v_{b f}=4 q / \pi T^{2}
\end{aligned}
$$

Where, $\mathrm{q}$ is volumetric flow rate of fluid leaving the impeller blades, $\mathrm{m}^{3}, \mathrm{~N}$ is revolutions per second; $\mathrm{D}$ is impeller diameter, $\mathrm{v}_{\mathrm{bf}}$ bulk fluid velocity, $\mathrm{m} / \mathrm{s}$ and $\mathrm{T}$ is tank diameter, $m$.

Finally, Reynold's number (Re), for non-Newtonian fluids measures the ratio of inertial to viscous forces within the mixing environment. The generalized Reynolds number is calculated from the following equation. [16]

\section{Results and Discussion}

\subsection{Flow Behavior of Orange Juice Concentrates}

Shear rate-Shear stress relations are plotted in Fig.1. for orange concentrate $(66 \mathrm{wt} \%)$ at different temperatures $(4,10$, $\left.30,40,50,60,70^{\circ} \mathrm{C}\right)$

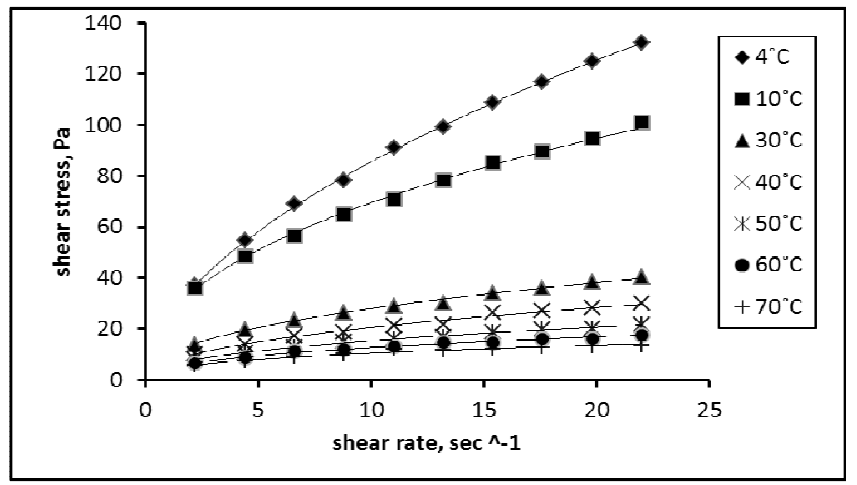

Figure 1. Relation between shear stress and shear rate at $66 \%$ solid concentration of orange juice and different temperature.

The results show that all the samples exhibited nonNewtonian pseudoplastic behavior at all the studied temperatures and concentrations.

Shear stress-shear rate data obtained fitted well to the constitutive equation:

$$
\tau=k \gamma^{n}
$$


Where, $\tau$ is the shear stress, $\mathrm{Pa}$

$\mathrm{k}$ is the plastic viscosity (consistency index)

$\gamma$ is the shear rate, $\sec ^{-1}$

$\mathrm{n}$ is the flow behavior index.

The values of flow behavior index (n) and consistency index $(\mathrm{k})$ at different temperatures are shown in Table 1.

Table 1. Relation between $k$, $n$ with temperature

\begin{tabular}{lll}
\hline Temperature, ${ }^{\circ} \mathbf{C}$ & $\mathbf{k}$ & $\mathbf{n}$ \\
\hline 4 & 24.02 & 0.531 \\
10 & 24.85 & 0.446 \\
30 & 9.986 & 0.447 \\
40 & 7.042 & 0.465 \\
50 & 5.651 & 0.433 \\
60 & 4.853 & 0.416 \\
70 & 4.349 & 0.38 \\
\hline
\end{tabular}

\subsection{Mixing of Orange Juice Concentrates}

\subsubsection{Power Calculation}

All the dimensionless numbers discussed in previous section are correlated with Reynold's number.

For calculating the power of the mixer, an impeller was connected to an Ammeter to measure the current at different revolutions per minute of the mixer.

$$
\mathrm{P}=\mathrm{I} \mathrm{V}
$$

Where $\mathrm{P}$ is the power of the mixer, watt, I is the current, Ampere, and $\mathrm{V}$ is the voltage, volt

\subsection{Effect of Impeller to Tank Diameter Ratio on Dimensionless Groups}

\subsubsection{Power Number - Reynolds Number Plot}

The Power number is analogous to a friction factor; it is proportional to the ratio of the drag force acting on a unit area of the impeller and the inertial stress; that is, the flow of momentum associated with the bulk motion of the fluid (McCabe, Smith, 2001) [17].

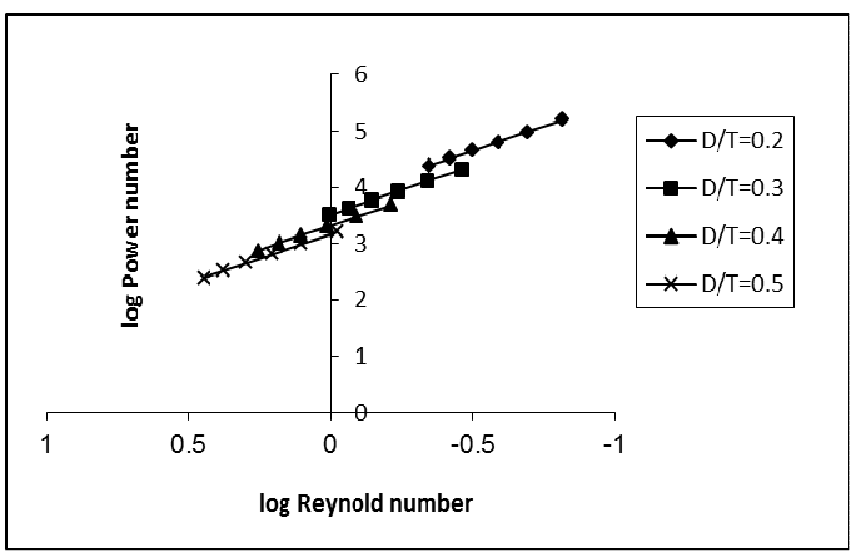

Figure 2. Relation between power number (Np) and Reynolds number of (Re) at different $\mathrm{D} / \mathrm{T}$ ratio.

The relation between Reynold's number and power number was fairly fitted to the following equation.

$$
\log N_{P}=\log A+B \log R e
$$

Where, $\mathrm{P}_{0}$ is the power number; Re is Reynold's number; $\mathrm{A}$ and $\mathrm{B}$ are constants.

Figure (2) shows the relation between power number and Reynold's number at different impeller to a column diameter $(\mathrm{D} / \mathrm{T})$ ratio.

\subsubsection{Blend Number - Reynolds Number Plot}

This correlation depicts the trends observed for flat-blade impeller type for different values of D/T. Fig. 3 shows that as $\mathrm{D} / \mathrm{T}$ increases, Reynolds number decrease (i.e., revolutions per second decrease) Blend number increases, (i.e., same time of mixing)

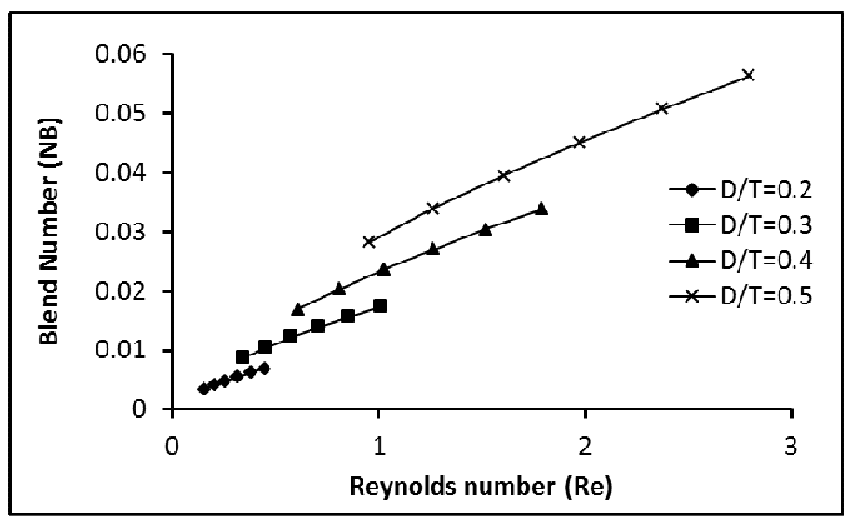

Figure 3. Relation between blend number $\left(N_{B}\right)$ and Reynolds number (Re) at different $\mathrm{D} /$ T ratio.

\subsubsection{Pumping Number- Reynolds Number Plot}

Figure (4) presents the effect of $\mathrm{D} / \mathrm{T}$ ratio on pumping number. Clearly the increase in $\mathrm{D} / \mathrm{T}$ ratio causes a decrease in pumping number at the same Reynolds number. This may be explained due to the fact that constant volumetric flow rate of fluid leaving impeller, q, requires the decrease of pumping number with an increase in impeller diameter.

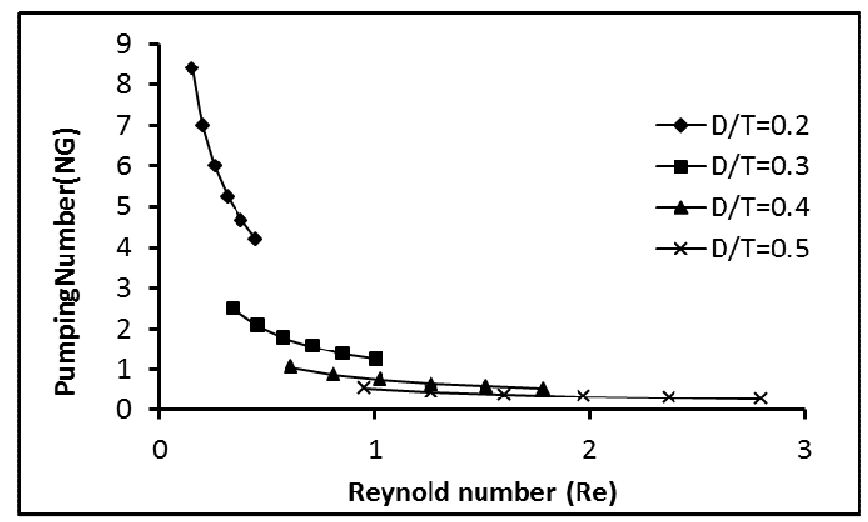

Figure 4. Pumping number $\left(N_{Q}\right)$ as function of Re at different $D /$ T ratio

\subsection{Mixer Scale-Up}

The scale-up procedure applied throughout this paper is based upon the assumption that lab-scale and plant-scale are geometrically similar and holding power per volume, $\mathrm{P} / \mathrm{V}$, fixed that is probably the most commonly used criterion in 
mixing scale-up because it is easily understandable and practical. Furthermore, fixed $\mathrm{P} / \mathrm{V}$ correlates well with mass transfer characteristics in the mixer, and it is conservative enough to provide adequate performance in production scale equipment.

To calculate $\mathrm{P} / \mathrm{V}$, rearrange Eq. 1 to solve for $\mathrm{P}$ and $\mathrm{V}$ is calculated by:

$$
V^{\prime}=\frac{\pi T^{2} Z}{4}
$$

Where, $\mathrm{V}^{\prime}$ is the tank volume, $\mathrm{m}^{3}, \mathrm{~T}$ is the tank diameter, $\mathrm{m}$, $\mathrm{Z}$ is the tank height, $\mathrm{m}$.

Table 2. contains the scale-up calculation summary of a plant-scale mixer. It is noticed that the successive increase in revolutions per second, $\mathrm{n}$, results in higher value of motor power, PM. Although the values of motor power (PM) range between $0.86-1 \mathrm{hp}$ for the investigated rotational speeds 34 $-87 \mathrm{rpm}$ respectively. The scale-up rule (based on fixed $\mathrm{P} / \mathrm{V}$ ) that must be applied to determine the plant-scale mixer speed $\left(\mathrm{n}_{\mathrm{ps}}\right)$ to be used to duplicate the lab-scale results using $\left(\mathrm{n}_{\mathrm{ls}}\right)$ is:

$$
\mathrm{n}_{\mathrm{ls}} \mathrm{D}_{\mathrm{ls}}^{2 / 3}=\mathrm{n}_{\mathrm{ps}} \mathrm{D}_{\mathrm{ps}}^{2 / 3}
$$

Where, $\mathrm{n}_{\mathrm{ls}}$ and $\mathrm{n}_{\mathrm{ps}}$ are revolutions per second in lab and plant scale, respectively; Dls and $\mathrm{D}_{\mathrm{ps}}$ are impeller diameter in lab and plant scale, respectively.

$$
\begin{gathered}
\mathrm{D}_{\mathrm{ls}}=0.08 \mathrm{~m}, \mathrm{~T}_{\mathrm{ls}}=\mathrm{Z}_{\mathrm{ls}}=0.34 \mathrm{~m} \\
\mathrm{D}_{\mathrm{ps}}=0.12 \mathrm{~m}, \mathrm{~T}_{\mathrm{ps}}=\mathrm{Z}_{\mathrm{ps}}=0.6 \mathrm{~m} \\
\mathrm{P}_{\mathrm{M}}=\mathrm{P} / 0.85
\end{gathered}
$$

Table 2. Summary of scale-up analysis for $D / T=0.2$

\begin{tabular}{lllllll}
\hline Run & $\mathbf{N}(\mathbf{r p s})$ & $\mathbf{R e}$ & $\mathbf{N}_{\mathbf{p}}$ & $\mathbf{P}, \mathbf{w a t t}$ & $\mathbf{P} / \mathbf{V}^{\prime}$ & $\mathbf{P}_{\mathbf{M}}, \mathbf{h p}$ \\
\hline Lab(1) & 0.833 & 0.271 & 37395.71 & 99 & 4697.613 & 0.156 \\
Plant(1) & 0.437 & 0.686 & 11465.02 & 549 & 4697.59 & 0.865 \\
Lab(2) & 1 & 0.359 & 23083.77 & 105.6 & 5109.307 & 0.166 \\
Plant(2) & 0.525 & 0.911 & 6998.837 & 597.123 & 5109.351 & 0.942 \\
Lab(3) & 1.166 & 0.456 & 15142.42 & 110 & 5184.903 & 0.173 \\
Plant(3) & 0.613 & 1.158 & 4611.012 & 605.87 & 5184.205 & 0.955 \\
Lab(4) & 1.333 & 0.562 & 10550.01 & 114.4 & 5375.499 & 0.18 \\
Plant(4) & 0.701 & 1.425 & 3212.242 & 628.2117 & 5375.375 & 0.991 \\
Lab(5) & 1.5 & 0.675 & 7694.591 & 118.8 & 5605.096 & 0.187 \\
Plant(5) & 0.788 & 1.711 & 2335.259 & 652.16 & 5605.292 & 1.028 \\
Lab(6) & 1.666 & 0.795 & 5713.234 & 121 & 5755.894 & 0.191 \\
Plant(6) & 0.876 & 2.016 & 1755.765 & 672.6 & 5755.189 & 1.061 \\
\hline
\end{tabular}

\section{Conclusion}

Orange concentrate exhibited non-Newtonian pseudoplastic fluid at temperatures $\left(4-70^{\circ} \mathrm{C}\right)$ and solid concentration $66 \%$ wt. An impeller mixer was used to predict the power number, blend number and pumping number as a function of Reynold's number at different impeller to tank diameter ratios at $10^{\circ} \mathrm{C}$ and $66 \%$ concentration. The effect of $\mathrm{D} / \mathrm{T}$ on $\mathrm{N}_{\mathrm{P}}, \mathrm{N}_{\mathrm{B}}$ and $\mathrm{N}_{\mathrm{Q}}$ was explainable. The design logic described throughout this paper depends on having reliable values of $\mathrm{N}_{\mathrm{P}}, \mathrm{N}_{\mathrm{B}}$ and $\mathrm{N}_{\mathrm{Q}}$ over the laminar flow regime for the impeller system being analyzed. These data allow selection of the appropriate scale-up criterion, ultimately leading to economic scale-up of pseudoplastic fluid mixing.

\section{Notation}

A and B are constants in equation (12), dimensionless.

D impeller diameter, $m$.

I current intensity, Ampere.

$\mathrm{k} \quad$ consistency index, Pa.sec

$\mathrm{n}$ revolutions per second

$\mathrm{N}_{\mathrm{P}} \quad$ power number

$\mathrm{N}_{\mathrm{B}} \quad$ blend number.

$\mathrm{N}_{\mathrm{Q}} \quad$ pumping number

$\mathrm{P} \quad$ power of the mixer, watt

$\mathrm{P}_{\mathrm{M}} \quad$ motor power, hp

$\mathrm{q} \quad$ volumetric flow rate of fluid leaving the impeller blades, $\mathrm{m}^{3}$

Re Reynolds number

$\mathrm{T} \quad$ tank diameter, $\mathrm{m}$

V voltage, volt

$\mathrm{V}^{\prime} \quad$ volume, $\mathrm{m}^{3}$

$\mathrm{Z} \quad$ liquid height in the tank, $\mathrm{m}$

$\gamma \quad$ shear rate, $\sec ^{-1}$

$\mu \quad$ Viscosity, Pa.sec

$\rho \quad$ Density, $\mathrm{kg} / \mathrm{m}^{3}$

$\tau \quad$ shear stress, $\mathrm{Pa}$

\section{References}

[1] K. Rajeev, Ch. Thakur, Vial, G. Djelveh, M. Labbafi, Mixing of complex fluids with flat-bladed impellers: effect of impeller geometry and highly shear-thinning behavior" Chemical Engineering and Processing, 43, pp. 1211-1222, 2004.

[2] Z. Maache-Rezzoug, J. M. Bouvier, K. Allaf, and C. Patras, Study of mixing in connection with the rheological properties of biscuit dough and dimensional characteristics of biscuits, J. Food Eng., 35, pp. 43-56, 1998.

[3] C. A. Kim, J. T. Kim, K. Lee, H. J. Choi, and M. S. Jhon, Mechanical degradation of dilute polymer solutions under turbulent flow, Polymer, 41, pp. 7611-7615, 2000.

[4] W. S. Kim, I. Hirasawa, and W. S. Kim, Effects of experimental conditions on the mechanism of particle aggregation in protein precipitation by polyelectrolytes with a high molecular weight, Chem. Eng. Sci, vol. 56, pp. 65256534,2001

[5] R. P. Chhabra, J.F. Richardson, Non-Newtonian Flow and Applied Rheology, Engineering Application, second ed. Elsevier, Butterworth-Heinemann, Amsterdam, 2008.

[6] A.W. Etchells, W.N. Ford, D.G.R. Short, Mixing of Bingham plastics on an industrial scale, Inst. Chem. Eng. Prog. Symp. Ser., 108, pp. 1-10, 1987. 
[7] S.R.Mostafa, and M.A. Sorour, Effect of impeller geometry on mixing of carrot concentrate. TESCE, 32, pp. 1-13, 2006.

[8] M.A. Sorour, Prediction of power number in mixing of apricot jam puree, Journal of Engineering and Applied Science, 53, pp. 133-144, 2006.

[9] S., Masiuk, T. J. Kawecka, Mixing energy measurements in liquid vessel with pendulum agitators, Chemical Engineering and Processing, 43, 91-99, 2004.

[10] C.B. Elias, J. B. Joshi, Role of hydrodynamic shear on activity and structure of proteins", In: Scheper, T. (Ed.), Advances in Biochemical Engineering/Biotechnology, Springer, 59, pp. 47-71, 1998.

[11] B. McNeil, L.M. Harvey, Viscous fermentation products. Critical Reviews in Biotechnology 13, pp. 275-304, 1993.

[12] S. Saito, K. Arai, K. Takahashi, M. Kuriyama, Mixing and agitation of viscous fluids., In: Cheremisinoff, N.P. (Ed.),
Encyclopedia of Fluid Mixing, vol. 2. Gulf Publishing, pp. 901-948, 1986.

[13] D.B. Todd, Mixing of highly viscous fluids, polymers, and pastes, In: Paul, E.L., Atiemo-Obeng, V.A., Kresta, S.M. (Eds.), Handbook of Industrial Mixing: Science and Practice. Wiley, pp. 987-1025, 2004.

[14] C. J. Geankoplis, 1983, Transport processes and unit operations, Allyn and Bacon, Inc., 2nd Ed., 1983

[15] R. J. Wilkens, C. Henry, L.E. Gates, Chemical Engineering Progress, pp. 44-52, 2003.

[16] Z. Xueming, H. Zondong, A. W. Nienowd, C.A. Kent, Rheological characteristics power consumption, mass and heat transfer during xanathan gum fermentation, Chinese Journal of Chemical Engineering, 2, pp. 198- 210, 1994.

[17] McCabe, W.L., and Smith, J.C., 2001, Unit Operations of Chemical Engineering, $6^{\text {th }}$ Ed., McGraw-Hill, New York, NY. 